\title{
Measurements of Flow around a Flap Side-Edge with Porous Edge Treatment
}

\author{
D. Angland* , X. Zhang ${ }^{\dagger}$ \\ University of Southampton, UK \\ L.C. Chow ${ }^{\ddagger}$ \\ Airbus UK, Filton, UK \\ and N. Molin ${ }^{\S}$ \\ Airbus France, Toulouse, France
}

\begin{abstract}
Wind tunnel experiments were performed to investigate a flap side-edge flowfield. A porous side-edge treatment was applied to a half span flap in an attempt to reduce the flap side-edge noise. Measurements taken were forces, on-surface pressures, particle image velocimetry, hotwire anemometry and on-surface microphones. Oil flow was performed to visualise the on-surface flow. Three potential acoustic sources were identified. The first two sources were the turbulent shear layer reattaching on the side-edge and on the upper surface. A mid-frequency broadband hump was measured by an on-surface microphone at the point of reattachment of the turbulent shear layer on the flap side-edge. The third source was a low frequency instability in the vortex due to non-linear vortical interactions upstream of the flap. This instability was measured by a hotwire in the downstream vortex and by an on-surface microphone in the main element flap cove. The effect of the porous side-edge was to reduce the magnitude of vorticity in the turbulent shear layer and the vortex. It was most noticeable in reducing the mid frequency broadband hump. It also had the effect of displacing the vortex further away from the flap surface. This reduced the magnitude of the low frequency perturbations from the unstable vortex that interacted with the solid surface.
\end{abstract}

\section{Nomenclature}

$b \quad$ Span of flap, $m$

c Reference chord, $\mathrm{m}$

$c_{F} \quad$ Flap chord, $\mathrm{m}$

$C_{D} \quad$ Drag coefficient

$C_{L} \quad$ Lift coefficient

$C_{M} \quad$ Pitching moment coefficient

$C_{p} \quad$ Pressure coefficient

$V_{\infty} \quad$ Freestream velocity, $\mathrm{m} / \mathrm{s}$

$x, y, z$ Cartesian coordinates, $x$ positive downstream, $y$ positive up, $z$ positive to port

$x_{F} \quad$ Distance along flap chord, $\mathrm{m}$

\section{Symbols}

$\alpha \quad$ Main element angle of attack, degrees

$\delta_{F} \quad$ Flap deflection angle, degrees

$\omega \quad$ Vorticity, $1 / \mathrm{s}$

${ }^{*}$ PhD Student, SES, University of Southampton, SO17 1BJ, UK.

${ }^{\dagger}$ Professor, SES, University of Southampton, SO17 1BJ, UK, Associate Fellow AIAA.

${ }_{\ddagger}^{\ddagger} \mathrm{PhD}$, Engineer, CoC Flight Physics, Building 09B, Filton, Bristol, BS99 7AR, UK.

$\S$ PhD, Engineer, EEA Department, 316 Route de Bayonne, PO Box M0112/4, 31060 Toulouse, Cedex 03, France. 


\section{Introduction}

$\mathrm{W}$ ITH civil aviation noise regulations becoming more stringent, noise reduction is becoming an increasingly important consideration for civil aircraft manufacturers. The noise generated by an aircraft comes mainly from two sources, the engine and airframe. Airframe noise is generated as the airframe moves through the air. The main contributors to airframe noise are landing gear and the high-lift devices. Noise of modern aircraft in their approach configuration can be dominated by airframe noise since the engines are normally operated at a reduced power setting.

A wind tunnel experiment was conducted to investigate the aerodynamics and aeroacoustics of a flap side-edge and the effect of applying porous materials to this region. Previous experimental work $^{1,2,3}$ has achieved noise reduction by replacing a part of the flap side-edge with brushes and an open cell porous edge. A noise reduction of up to $4 \mathrm{~dB}$ in the farfield was reported, within a limited band of frequencies. The physics responsible for this noise reduction were not discussed.

Various three-dimensional steady Reynolds-Averaged Navier-Stokes (RANS) computations have also identified major flow physics present in the flap side-edge region. ${ }^{4,5,6,7}$ Choudhari et al. ${ }^{8}$ performed a computational study of a porous flap side-edge as a passive means for flap noise reduction. Since the nearfield unsteadiness was not modelled, it was not possible to translate the flow alterations into accompanying reductions in sound pressure level (SPL). Importantly, the damping effect of the finite impedance of the porous material on the pressure fluctuations was not modelled. The present work employed a variety of experimental techniques to understand the physical mechanism by which the porous side-edge reduced the noise.

\section{Experimental Apparatus and Procedure}

\section{A. Wind Tunnel}

The experiments were conducted in the University of Southampton $3.5 \mathrm{~m} \times 2.5 \mathrm{~m}$ wind tunnel. The tunnel was a closed circuit return type with a closed working section. The freestream turbulence level was less than $0.3 \%$ at $30 \mathrm{~m} / \mathrm{s}$. The wind tunnel incorporated a chiller that maintained the air temperature at 19 degrees C.

\section{B. Model Design and Test Configuration}

The wing used in the experiments was of a high lift design with a fixed leading edge and a half span trailing edge flap, shown in Figure 1. The origin of the axis system was at the leading edge of the main element in the $x-y$ plane and at the flap side-edge in the $z$ direction. The chord of the main element was $0.71 \mathrm{~m}$ and the span was $1 \mathrm{~m}$. The chord and span of the trailing edge flap were $0.198 \mathrm{~m}$ and $0.5 \mathrm{~m}$ respectively. The reference length, based on the retracted chord of the model, was $0.8 \mathrm{~m}$. The main element was machined from wood and the half-span flap was made from carbon-fibre skins and machined aluminium ribs. The main element was fitted with 45 pressure taps along the mid-chord and with 5 microphones; 3 around the nose and 2 in the flap cove region. The half span flap was pressure tapped around the mid-chord with 20 taps and also contained 15 taps in the spanwise direction. The half-span flap also contained a microphone, flush mounted at the flap side-edge at $x_{F} / c_{F}=0.27$. The positions of the two on-surface microphones are shown in Figure 2. The range of Reynolds numbers tested were $0.6 \times 10^{6}$ to $2.0 \times 10^{6}$, based on the reference length. The angle of attack range was 0 degrees to 15 degrees and the flap deflection range was 29 degrees to 39 degrees.

Experiments were performed with a hardwall and a porous flap side-edge with a porosity of 40 Pores Per Inch (PPI) and a density of $10-12 \%$. The porous treatment was applied to $0.02 \mathrm{~m}$ of the span of the flap, which corresponded to $4 \%$ of the span of the flap. The porous side-edge is shown in Figure 3. Measurements conducted included forces, surface pressures, particle image velocimetry (PIV), hotwire anemometry and on-surface microphones.

\section{Forces}

The wind tunnel contained a six-component balance with Nutem load cells. Only lift, drag and pitching moment are presented in the results section. The force data was averaged over three runs. The repeatability 
for $C_{L}$ and $C_{D}$ was within $1.6 \%$ and for $C_{M}$ the repeatability was within $2.1 \%$. The angle of attack of the main element was set to \pm 0.05 degrees. The freestream values of temperature, static pressure and velocity were averaged from the values at the beginning and the end of each run. The average variations between the start and the end of the run were $\pm 0.5{ }^{\circ} \mathrm{C}$ for temperature, $\pm 0.1 \mathrm{mmH}_{2} \mathrm{O}$ for pressure and $\pm 0.01 \mathrm{~m} / \mathrm{s}$ for velocity. The reference planform area used in the calculation of the coefficients was $0.8 \mathrm{~m}^{2}$. The reference chord was $0.8 \mathrm{~m}$.

\section{Pressure Measurements}

The pressures were measured using a ZOC (Zero, Operate and Calibrate) system from Scanivalve Inc. This system used an individual piezoresistive differential pressure sensor for each channel. The data was acquired using a Pi Research Ltd Mistral system. The time averaged pressure at each port was averaged over 30 seconds. The short term repeatability of the on-surface pressures was within $1 \%$.

\section{E. Particle Image Velocimetry}

PIV is a non-intrusive technique providing instantaneous velocity vector measurements in a cross-section of a flow. The fluid was seeded with particles typically in the range $1 \mu \mathrm{m}$ to $5 \mu \mathrm{m}$. The seeding particles needed to be small enough so that they followed the flow accurately. They also needed to be small in comparison to flow structures in the flowfield so that the velocity did not change significantly across the seeding particle. The seeding particles in the plane of interest were illuminated with a laser sheet. The laser system used consisted of two Gemini Nd:YAG lasers that were capable of running at $4 \mathrm{~Hz}$, emitting $120 \mathrm{~mJ}$ pulses at $532 \mathrm{~nm}$. The position of these particles were recorded on a CCD digital camera at two different times, 10 $\mu \mathrm{s}$ apart.

The laser was placed in a room on the port side of the working section. The laser sheet was pointed in a vertical plane through a glass window, which makes up one wall of the working section and then through a second glass window that formed part of the endplate. The laser was mounted on a one-dimensional traverse that was placed parallel to the mean flow direction so that it could easily be moved from one plane to another. The camera was attached to a strut, which was mounted from the floor to the ceiling of the wind tunnel approximately 10 chord lengths downstream of the model. This allowed $y-z$ planes through the vortex core to be examined. The smoke generator was placed aft of the working section. This ensured the smoke had sufficiently diffused to ensure a homogeneity in seeding levels by the time the smoke reached the model.

The cross correlation was performed on interrogation areas measuring $32 \times 32$ pixels. The horizontal and vertical overlap was $75 \%$. A peak validation of 1.2 was used to reject spurious vectors. The time averaged data was averaged over 300 images.

\section{F. Hotwire Anemometry}

A single hotwire was used for one component velocity measurements. The principle of hotwire anemometry is that the convective heat transfer is a function of the velocity, the wire over-temperature and the physical properties of the fluid. The hotwire used was made of tungsten and was $5 \mu \mathrm{m}$ in diameter. An analog to digital converter was used to convert the voltages from the bridge to a digital signal.

The hotwire probe was placed on a one-dimensional traverse placed vertically, which allowed the hotwire to traverse through the vortex core. The hotwire was calibrated in freestream using a pitot-static tube connected to a digital micromanometer. The turbulence intensity was less than the $0.5 \%$ as recommended by Bruun. ${ }^{9}$ The calibration was performed from $0 \mathrm{~m} / \mathrm{s}$ to $36 \mathrm{~m} / \mathrm{s}$ in steps of $3 \mathrm{~m} / \mathrm{s}$. The average error in the hotwire for the calibration run was $0.32 \%$.

\section{G. Microphones Measurements}

The microphones used were Panasonic WM-60A omnidirectional condenser microphones. These were flush mounted onto the surface of the model. The sensitivity was $-44 \pm 5 \mathrm{~dB}$. The measurable frequency range was $20-20000 \mathrm{~Hz}$. The operating voltage was $2 \mathrm{~V}$ provided by the preamps and the signal to noise ratio was greater than $58 \mathrm{~dB}$. The typical frequency response curve, supplied by the manufacturer, showed that the relative response was constant across the frequency range. 


\section{Results and Discussion}

\section{A. Forces}

The lift, drag and pitching moment results are shown in Figures 4 - 6 adjusted for wind tunnel blockage correction factors. ${ }^{10}$ The lift and drag forces demonstrated Reynolds number independence over the angle of attack range measured within the bounds of repeatability. A change in slope in the $C_{L}$ curve occured at an angle of attack of approximately 2.5 degrees. This angle of attack corresponded to the onset of trailing edge separation of the flap. As the angle of attack increased further, the separation line moved further upstream along the flap suction surface. The pitching moment was measured about the mount points on the main element, which were located at $x=0.26 \mathrm{~m}$. The pitching moment was defined as positive about the $z$ axis, i.e. nose down. Initially due to the deflection of the flap, the centre of pressure was located significantly aft of the mount points and therefore corresponded to a positive pitching moment coefficient. As the angle of attack of the main element increased, the separation on the flap covered more of the surface. This resulted in the centre of pressure moving forward towards the pivot point thereby reducing the pitching moment. This region of the pitching moment coefficient curve showed significant Reynolds number dependence since the centre of pressure was dependent on the separation location on the flap suction surface.

\section{B. Surface Pressures}

The results for the pressure distribution over the main element and the flap at two different angles of attack at a Reynolds number of $1.1 \times 10^{6}$ are presented in Figure 7 . Just aft of the peak suction on the nose of the main element there was a separation bubble. This was indicated by the small decrease in pressure before the bubble at $x / c=0.02$. The pressure distribution flattened over the length of the bubble and was then followed by a very sharp adverse pressure gradient at $x / c=0.06$. This point corresponded to the end of the bubble where the flow reattached to the surface. The presence of the flap cove at $x / c=0.72$ can be seen on the pressure surface of the main element. Immediately behind the cove the flow was separated and this caused a decrease in the pressure. The pressure then increased towards the point where the shear layer reattached onto the cove surface. As the flow accelerated through the flap gap, the pressure again decreased. The pressure distribution in the cove region appeared not to be influenced by the angle of attack, within the range of angles measured. Oil flow visualisation showed that the flow was clearly separated at this spanwise location. However, it was difficult to detect the separation point on the pressure distribution over the flap at both angles of attack. The spanwise pressure distribution on the flap is shown in Figure 8. At $y / b \geq 0.9$ the pressure distribution showed a large and sudden decrease in pressure. This was due to the presence of the endplate.

\section{Oil Flow}

Near the leading edge of the flap, evidence of a dual vortex system can be seen. The main vortex separated from the lower edge of the flap and reattached along the primary attachment line, shown in Figure 9. Because of the sharp edge, the separation line was fixed at the bottom edge. At the upper edge of the flap a secondary vortex separated from the sharp edge and reattached on the suction surface of the flap on the secondary vortex reattachment line, as indicated in Figure 10. The main vortex grew rapidly in size in the streamwise direction as evidenced by the primary attachment line moving towards the suction surface of the flap side edge. At the primary attachment line, the flow stagnated and divided into streaklines that flowed towards the upper and lower surface. The flow above the stagnation line separated from the upper edge to form the secondary vortex, which reattached on the suction surface of the flap. The flow on the lower half on the stagnation line separated at the secondary separation line before it reached the lower edge. This is shown in the schematic in Figure 11. This formed a small region of separation that grew slowly in the streamwise direction just above the lower edge of the flap, since it was dominated by the stronger primary vortex on the side-edge. As the vortices on the side-edge and upper surface merged, they separated from the flap surface.

A focal point was situated on the edge between the side-edge and the suction surface of the flap at approximately two thirds of the flap chord. This was evidenced by an accumulation of oil during the run. Aft of this focal point the flow was reversed as seen in Figure 10. Khorrami et al. ${ }^{4,5}$ noted a similar phenomenon located entirely on the side edge. In the oil flow performed in this experiment the location of the focal point was higher up and had moved onto the suction surface. This was caused by a change in the spanwise location of the off-surface vortex. 


\section{Particle Image Velocimetry}

\section{Hardwall}

The nearfield formation and evolution of the vortex was examined using PIV in five $y-z$ planes along the flap chord, which are tabulated in Table 1. The nearfield flow structures were then related to the nearfield unsteadiness and potential acoustic sources. Similar flow features were found as reported by other authors. ${ }^{5}$

\begin{tabular}{|c||c|}
\hline PIV Plane & $x_{F} / c_{F}$ \\
\hline 1 & 0.2 \\
2 & 0.4 \\
3 & 0.6 \\
4 & 0.7 \\
5 & 0.8 \\
\hline
\end{tabular}

Table 1. PIV Planes.

The presence of a dual vortex system and vortex merging were captured. The off-surface vortex, one chord length aft of the flap trailing edge, was also examined using PIV for both the hard wall and the porous side-edge cases. This vortex showed significant wandering in the PIV measurements. This wandering was caused by the unsteady flow originating upstream of the flap. A shear layer separated from the sharp cusp in the flap cove region on the main element. This shear layer had an inflectional instability, which led to a low frequency pressure disturbance in the cove region. The vorticity that was produced in the shear layer was convected through the flap gap above the flap suction surface. Vorticity was also shed from the blunt main element trailing-edge. These two sources of vorticity contained different length scales and were convected at different speeds. They interacted above the flap suction surface to produce a significantly unsteady flowfield. Another source of vorticity was in the separated wake of the flap on the suction surface. Therefore, the flap side-edge vortex was formed in a highly unsteady flowfield caused by all the non-linear interactions of vortical flowfields. This provided the necessary perturbations for instabilities to grow. The proposed sources of vorticity in the $x-y$ plane are shown schematically in Figure 12. The potential acoustic sources arising from voritcity-surface interactions are illustrated schematically in Figure 13. These will be discussed as they arise in the PIV measurements.

Plane 1 for the hardwall case is shown in Figure 14(a). The presence of a dual vortex system with the primary vortex attaching on the flap side-edge and a significantly weaker vortex on the suction surface can be seen. The shed vorticity from the wake of the main element can also be seen. The deflection of this wake due to the presence of the vortex was minimal at this plane since the strength of the vortex was small. Significant on-surface unsteadiness was produced where the turbulent shear layer impinged on the flap sideedge as shown schematically in Figure 13(a). Plane 2, which corresponded to the point of vortex merger, is displayed in Figure 14(b). At this plane the primary vortex attachment line moved to the suction surface of the flap. The effect of the vortex on the main element wake can be seen in this plane. Due to the induced flowfield caused by the vortex, the wake vorticity was displaced away from the surface outboard but brought closer to the flap surface inboard of the side-edge. As the vortex grew in strength and separated from the flap surface, the main element wake vorticity was wrapped around the vortex and convected onto the solid surface of the flap. This non-linear interaction of vorticity was a significant source of unsteadiness and led to a significantly unsteady vortex. This is illustrated in Figure 13(b).

The third plane is displayed in Figure 14(c). This plane showed the vortices merged into a single large vortex whose reattachment point was on the flap suction surface. The vortex grew rapidly in the streamwise direction and the strength of vorticity in the shear layer increased. Plane 4, which is shown in Figure 14(d), shows the vortex which is now detached from the surface. As the vortex grew in strength, the seeding particles were forced from the centre of the vortex due to the centrifugal force of the spinning vortex. This can clearly be seen by the lack of vectors in the vortex core. The unsteady pressure field induced by the off-surface vortex interacted with the flap suction surface and sharp side-edges as illustrated in Figure 13(c). The fifth and final plane, just upstream of the trailing-edge, is displayed in Figure 14(e). The vortex exhibited significant unsteadiness constantly fed from the shear layer that originated from the lower surface of the flap side-edge. 


\section{Porous Side-Edge}

The PIV images presented in Figure 15 are for a porous side-edge of porosity 40 PPI and a density 10 - 12 \%. It was difficult to obtain adequate PIV data near the surface due to reflections and diffraction of the laser light sheet from the open cell porous material. One effect of the porous side-edge was to reduce the strength of the vortex by easing the pressure differential between the suction and the pressure surfaces. The combination of a low strength vortex attached to the surface and excessive reflections meant that no useable data could be obtained for plane 1. The second plane, shown in Figure 15(a), shows the reduced vorticity in the vortex due to the porous side-edge.

Plane 3, displayed in Figure 15(b), shows the elongated vortex in the vertical direction. This was due to the mass flow rate through the porous material from the pressure surface to the suction surface. This had the effect of displacing the vortex away from the suction surface. The vortex was a significant source of unsteadiness, due to the nonlinear vortical interactions. Since it was located above a solid surface with sharp edges, it was a significant acoustic source. The displacement of this unsteadiness away from the solid surface had the advantage of reducing the acoustic source strength. It is likely that the air passing through the open cell material would create a turbulent jet effect when exiting to the air above the flap. This would be a very high frequency source of noise. However, this was not picked up in the microphone measurements presented later. Therefore, this high frequency source was either beyond the threshold of measurement or the magnitude was so small it was lost beneath the background noise.

The fourth and fifth planes are displayed in Figures 15(d)-(e). The effect of the porous side-edge was to reduce the strength of the shear layer that was wrapped around the vortex and to displace the vortex further away from the solid surface.

\section{E. Hotwire Anemometry}

Hotwire measurements were made of the vortex core and the surrounding flow five chord lengths downstream of the flap trailing edge. This was to determine the unsteadiness inherent in the fully-formed, off-surface vortex for the hardwall case. Three different $y$ positions were measured, which corresponded to the centre of the vortex core at three specific test conditions. These are tabulated in Table 2.

\begin{tabular}{|c||c|}
\hline Hotwire Position & Vortex Core at Test Conditions \\
\hline 1 & $\alpha=5^{\circ}, \delta_{F}=29^{\circ}$ \\
2 & $\alpha=10^{\circ}, \delta_{F}=29^{\circ}$ \\
3 & $\alpha=10^{\circ}, \delta_{F}=39^{\circ}$ \\
\hline
\end{tabular}

Table 2. Hotwire Positions.

At the first position measured, the vortex showed a triple peak tonal feature with peaks at $290 \mathrm{~Hz}$, $340 \mathrm{~Hz}$ and $390 \mathrm{~Hz}$. The main element angle of attack was 5 degrees and the flap deflection angle was 29 degrees (Figure 16(a)). The strongest tonal feature occurred at a frequency of $670 \mathrm{~Hz}$ before the drop off in the energy cascade. As the main element angle of attack was increased to 10 degrees (Figure 16(b)) a tone appeared at $270 \mathrm{~Hz}$ and a smaller broadband like peak centered around $470 \mathrm{~Hz}$. This was due to the change in trajectory of the vortex as the main element angle of attack was increased. At 5 degrees angle of attack the hotwire probe was in the centre of the vortex. At 10 degrees angle of attack the hotwire probe was outside of the vortex. As the vortex moved even further away from the hotwire probe the velocity fluctuations dissipated rapidly (Figure 16(c)). The low frequency feature measured at $470 \mathrm{~Hz}$ on the edge of the vortex was due to the wandering of the vortex. The frequency at this airspeed matched the frequency measured in the flap cove by the on-surface microphone. This suggested that the wandering of the vortex was driven by unsteadiness originating in the flap cove on the main element.

The second position corresponded to the centre of the vortex at an angle of attack of 10 degrees and a flap deflection angle of 29 degrees. At an airspeed of $10 \mathrm{~m} / \mathrm{s}$ (Figure 16(d)) the main tonal feature was at 504 $\mathrm{Hz}$ with its associated harmonics for a main element angle of attack of 10 degrees At $20 \mathrm{~m} / \mathrm{s}$ (Figure 16(e)) the main tonal feature was at $1340 \mathrm{~Hz}$ measured in the centre of the vortex core. This was the streamwise instability of the vortex. A broadband peak was centered around $2560 \mathrm{~Hz}$ and a tonal peak occurred at 4000 $\mathrm{Hz}$. These frequencies matched the frequencies of the turbulent shear layer shed from the flap side-edge as 
measured by the on-surface microphone. At an airspeed of $30 \mathrm{~m} / \mathrm{s}$ (Figure 16(f)) the main tonal feature had a frequency of $1930 \mathrm{~Hz}$.

The third position corresponded to the edge of the vortex at 10 degrees angle of attack and 39 degrees flap deflection angle. The low frequency tonal instabilities of the laminar vortex core were no longer measured as distinctly as before. Instead mid-frequency instabilities that were slightly more broadband in nature were measured. At $10 \mathrm{~m} / \mathrm{s}$ (Figure 16(g)) three broadband peaks occurred that were centered around $2100 \mathrm{~Hz}$, $3600 \mathrm{~Hz}$ and $4880 \mathrm{~Hz}$. Similar to before these features were due to shed vorticity from the turbulent shear layer at the flap side-edge.

\section{F. Microphones}

On-surface microphone measurements were made on the main element cove and on the flap side-edge using omni-directional microphones. Furthermore, microphones were placed in different locations around the model and test section, to determine tonal components of the spectrum that were clearly due to noise associated with running the wind tunnel and not aerodynamic phenomena associated with the model.

Four microphones were used to record the nearfield acoustics. Mic 1 was situated flush mounted on the flap side-edge at $x_{F} / c_{F}=0.27$, Mic 2 was placed on the tail bar pointing towards the flap side-edge at $x_{F} / c_{F}=0.8$ and Mic 3 was flush mounted on the starboard endplate pointing towards the flap side-edge at $x_{F} / c_{F}=0.4$. Mic 4 was flush mounted on the main element flap cove to measure the unsteadiness upstream of the flap in the cove region.

For the hardwall case the most notable feature in the spectra was the presence of a broadband hump measured from the microphone flush mounted to the flap side-edge (Mic 1). The characteristics of this feature depended on airspeed and flap deflection angle. This broadband hump was centered around a frequency of $4000 \mathrm{~Hz}$ at $10 \mathrm{~m} / \mathrm{s}$. This broadband hump was due to the impingement of the turbulent shear layer onto the flap side-edge. The microphone was placed on the primary attachment line determined from the oil flow at a flap deflection angle of 29 degrees. At the flap deflection of 29 degrees the broadband peak was centered around $69 \mathrm{~dB}$ at $4050 \mathrm{~Hz}$ (Figure 17(a)). As the flap deflection angle increased to 39 degrees the broadband peak was centered around $60 \mathrm{~dB}$ at $4200 \mathrm{~Hz}$ (Figure 17(b)). The reason for the reduction in SPL at the increased flap deflection angle, was that the microphone was no longer directly on the primary attachment line. The slight shift in frequency indicated a decrease in the length scales responsible for the disturbance due to the modified flow velocities around the flap side-edge at the higher deflection angle.

As the airspeed increased to $20 \mathrm{~m} / \mathrm{s}$, there was a double peak in the broadband hump. This showed there were two length scales responsible for the nearfield noise. At a flap deflection angle of 29 degrees the second peak was dominant at $4500 \mathrm{~Hz}$ and $89 \mathrm{~dB}$ (Figure $17(\mathrm{c})$ ). At the 39 degrees flap deflection case a new peak appeared at $7200 \mathrm{~Hz}$ at a magnitude of $76 \mathrm{~dB}$. At an airspeed of $30 \mathrm{~m} / \mathrm{s}$ (Figure 17(e)) the broadband feature displays three distinct peaks at a flap deflection angle of 29 degrees. The third peak was at a frequency of $6500 \mathrm{~Hz}$ and a magnitude of $94 \mathrm{~dB}$. As the flap deflection angle was increased to 39 degrees the three peaks merged into two distinct peaks (Figure 17(f)). The second peak was centered around $8500 \mathrm{~Hz}$ and had a magnitude of $88 \mathrm{~dB}$. This broadband hump showed dependence on the flap deflection angle and airspeed but was insensitive to the main element angle of attack.

In the cove region of the main element, weak tonal features were measured at $460 \mathrm{~Hz}$ and $1120 \mathrm{~Hz}$ at 10 $\mathrm{m} / \mathrm{s}$ with Mic 4, as shown in Figure 18(c). As the airspeed increased to $20 \mathrm{~m} / \mathrm{s}$ these tonal features were lost beneath the boundary layer noise of the flow over the microphone. The origin of these tones was the unsteady pressure field induced by the inflectional instability of the shear layer. The instabilities at this point, due to the shed vorticity from the cove, were important as they were convected through the flap gap and interacting with the side-edge vortex.

The effect of adding the porous material to the flap side-edge was to dramatically reduce this broadband hump. Low frequency tonal features, at magnitudes similar to the hardwall case, were detected from $100 \mathrm{~Hz}$ to $1000 \mathrm{~Hz}$. At $10 \mathrm{~m} / \mathrm{s}$ the broadband peak was centered at $4400 \mathrm{~Hz}$, slightly higher than the $4050 \mathrm{~Hz}$ of the hardwall case (Figure 19(a)). The SPL at the centre of the peak was $40 \mathrm{~dB}$ which represented a drop of $39 \mathrm{~dB}$ compared to the rigid flap side-edge due to the displacement effect. By reducing the magnitude of vorticity in the turbulent shear layer and displacing the vortex further away from the surface, the acoustic source has been reduced. Care must be taken however since these are nearfield measurements and cannot be directly related to a farfield reduction in sound. 


\section{Conclusions}

The aerodynamic properties of a high lift wing equipped with a half span flap were determined by means of on-surface pressures and by measuring forces and moments. PIV was used to examine the formation of the vortex with both a hard wall and a porous side-edge. Oil flow visualisation was performed in conjunction with the PIV to determine the nearfield flow. From the flow visualisation and PIV measurements three potential noise sources were proposed at the flap side-edge. Firstly, near the leading edge, the turbulent shear layer that separated from the pressure surface of the flap, attached to the side-edge. An on-surface flush mounted microphone was placed at this attachment point to measure the unsteadiness caused by the impingement of the turbulent shear layer. Secondly, near the mid-chord of the flap, the dual vortex system on the flap side-edge had merged to become a single vortex. The attachment point of the turbulent shear layer now moved to the upper surface. The location of the source and the length scales responsible for it had changed. Thirdly, as the trailing edge was approached, the vortex was located off-surface above the flap side-edge. The vortex exhibited a low frequency instability due to unsteady flow originating upstream of this point. This caused pressure perturbations from the wandering vortex to interact with the sharp flap side-edge and trailing edge.

By applying a porous side-edge to the flap, the PIV measurements showed that the magnitude of vorticity in the shear layer wrapped around the vortex was reduced compared to that of the hard wall case. Also the vortex itself was weaker. The porous side-edge also had the desirable effect of displacing the vortex further away from the solid surface thereby reducing its strength as an acoustic source.

From the hotwire measurements, the vortex downstream of the flap exhibited low frequency instabilities centered around $470 \mathrm{~Hz}$ at $10 \mathrm{~m} / \mathrm{s}$. This corresponded to the on-surface microphone measurements in the cove region of the main element where a similar frequency was measured at the same airspeed. This suggested that the low frequency instabilities in the downstream vortex were dominated by unsteadiness originating upstream of the flap. The spectra also demonstrated mid frequency features between 2000 and $5000 \mathrm{~Hz}$, which became slightly more prominent as the freestream velocity increased. These frequencies matched those measured by the on-surface microphone at the flap side-edge. The origin of these instabilities was shed turbulence from the flap side-edge.

Although the mid frequency disturbances were small as measured by the hotwire far downstream, they dominated the nearfield. The on-surface microphone, located at the primary vortex attachment line, showed a broadband hump between $2000 \mathrm{~Hz}$ and $7000 \mathrm{~Hz}$ depending on airspeed and flap deflection angle. The effect of increasing the flap deflection angle was to decrease the magnitude of these disturbances, since the vortex separated from the flap surface further upstream. Therefore, for the 39 degree flap deflection case the vortex was already off-surface and therefore the shed turbulence was moved further away from the onsurface microphone. The effect of the porous side-edge treatment was to reduce this nearfield mid frequency broadband feature by displacing the vortex away from the side-edge and by reducing the strength of the shed vorticity feeding the vortex.

\section{Acknowledgements}

David Angland wishes to thank the School of Engineering Sciences, University of Southampton for providing a research studentship. The research funding for this project is provided by Airbus. 


\section{References}

${ }^{1}$ Chow, L. C., Mau, K., and Remy, H., "Landing Gear and High Lift Devices Airframes Noise Research," AIAA Paper 2002-2408, 2002.

${ }^{2}$ Macaraeg, M. G., "Fundamental Investigations of Airframe Noise," AIAA Paper 98-2224, 1998.

${ }^{3}$ Meadows, K. R., Brooks, T. F., Humphreys, W. M., Hunter, W. W., and Gerhold, C. H., "Aeroacoustic Measurements of a Wing-Flap Configuration," AIAA Paper 97-1595, 1997.

${ }^{4}$ Khorrami, M. R., Berkman, M. E., Li, F., and Singer, B. A., "Computational Simulations of a Three-Dimensional High-Lift Wing," AIAA Paper 2002-2804, 2002.

${ }^{5}$ Khorrami, M. R., Singer, B. A., and Radeztsky, R. H., "Reynolds-Averaged Navier-Stokes Computations of a Flap-SideEdge Flowfield," AIAA Journal, Vol. 37, No. 1, 1999, pp. 14-22.

${ }^{6}$ Street, C. L., "Numerical Simulation of a Flap-Edge Flowfield," AIAA Paper 98-2226, 1998.

${ }^{7}$ Brooks, T. F. and Humphreys, W. M., "Flap Edge Aeroacoustic Measurements and Predictions," AIAA Paper 2000-1975, 2000.

${ }^{8}$ Choudhari, M. and Khorrami, M. R., "Computational Study of Porous Treatment for Altering Flap Side-Edge Flow Field," AIAA Paper 2003-3113, 2003.

${ }^{9}$ Bruun, H. H., Hot-Wire Anemometry, Oxford University Press, 1995.

${ }^{10} \mathrm{ESDU}$ 80024, Blockage Corrections for bluff bodies in confined flows, 1998. 


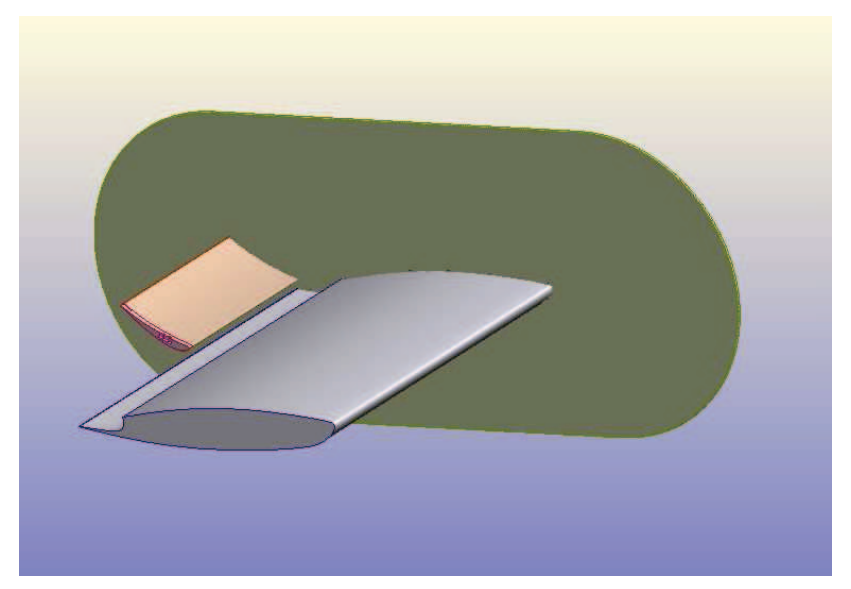

Figure 1. Wind tunnel model with port side endplate removed. Flow is from right to left.

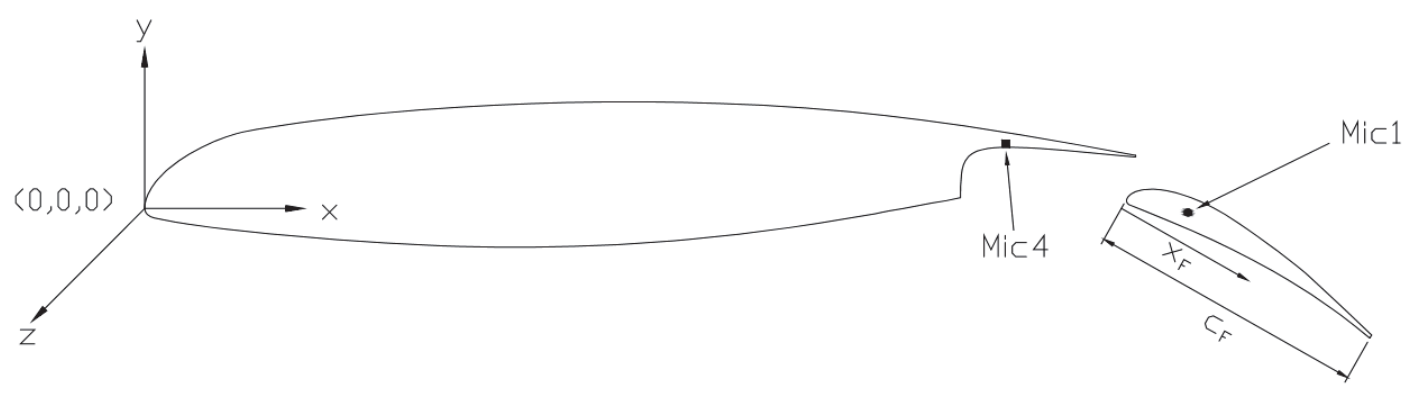

Figure 2. Geometry showing the definition of axes and location of microphones. Flow is from left to right.

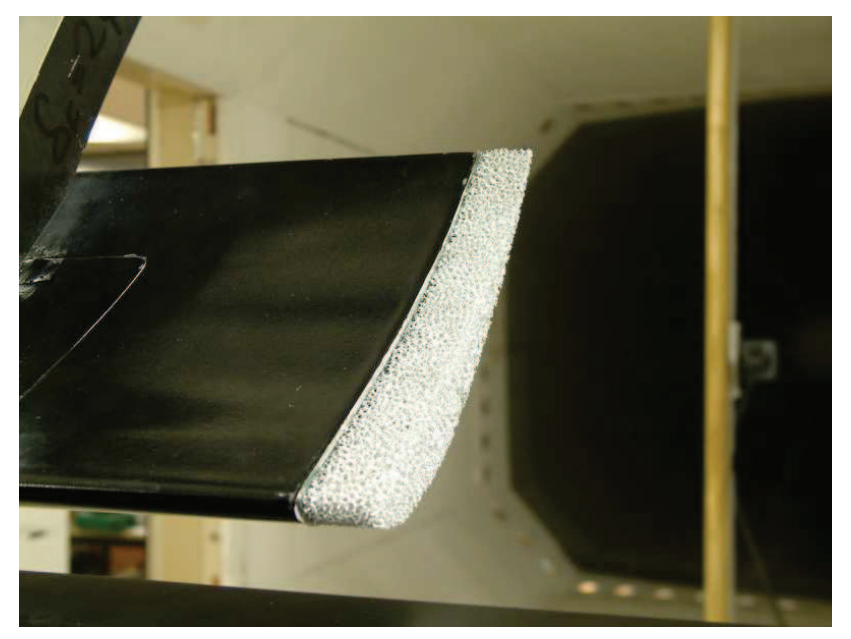

Figure 3. A downstream view of the porous flap side-edge. The PIV camera can be seen mounted on the strut in the background. The laser sheet shines from right to left in the vertical plane.

\section{0 of 22}




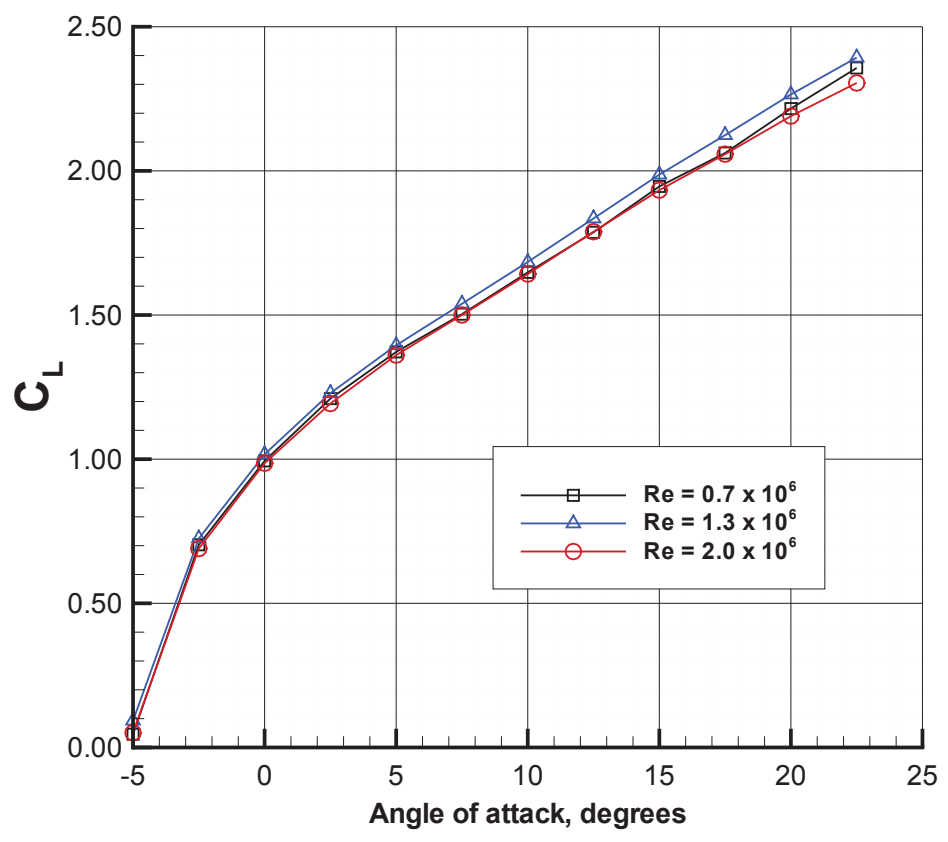

Figure 4. $C_{L}$ variation with angle of attack.

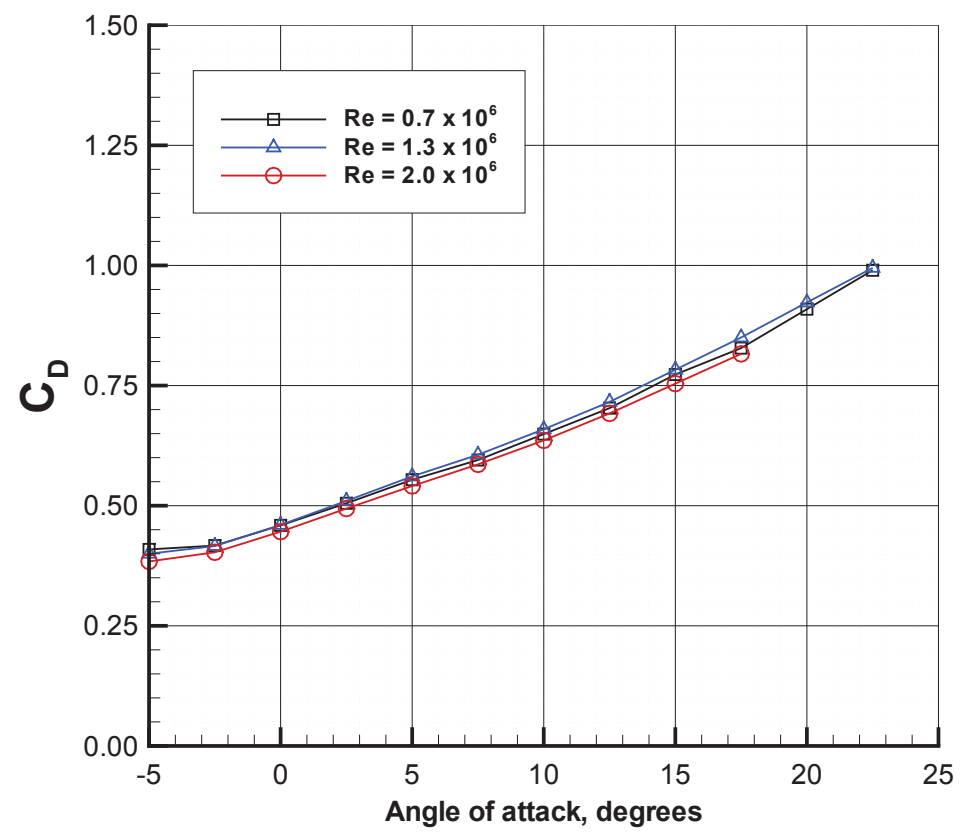

Figure 5. $C_{D}$ variation with angle of attack.

\section{1 of 22}




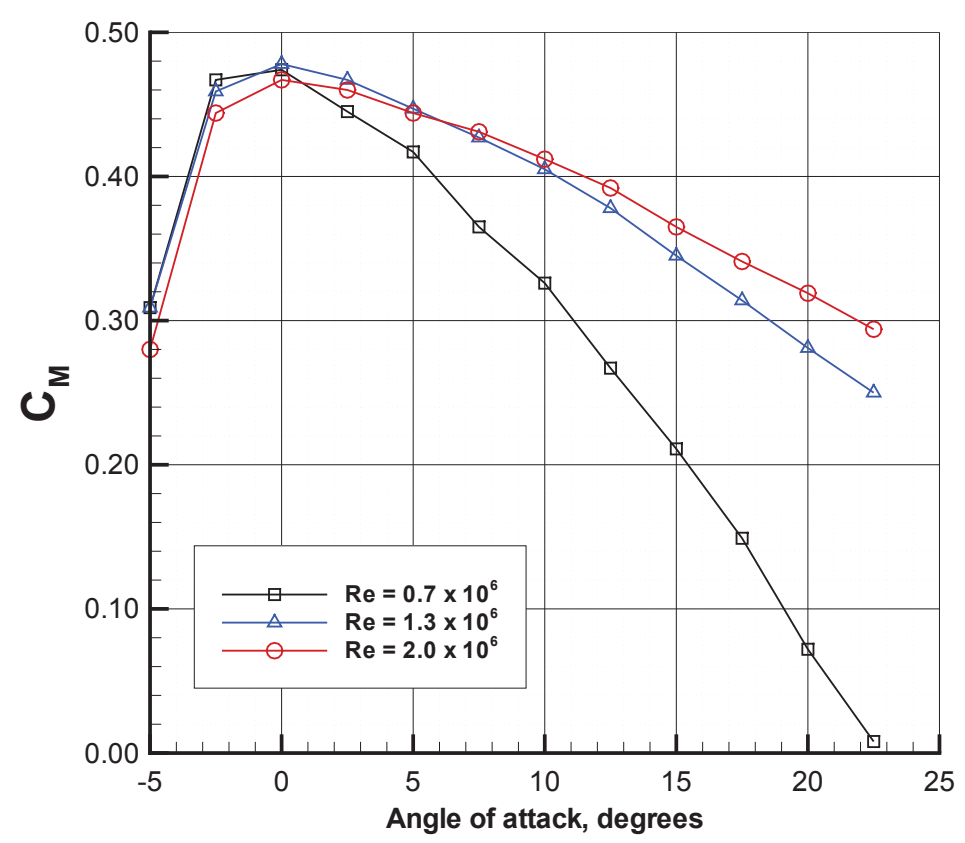

Figure 6. $C_{M}$ variation with angle of attack.

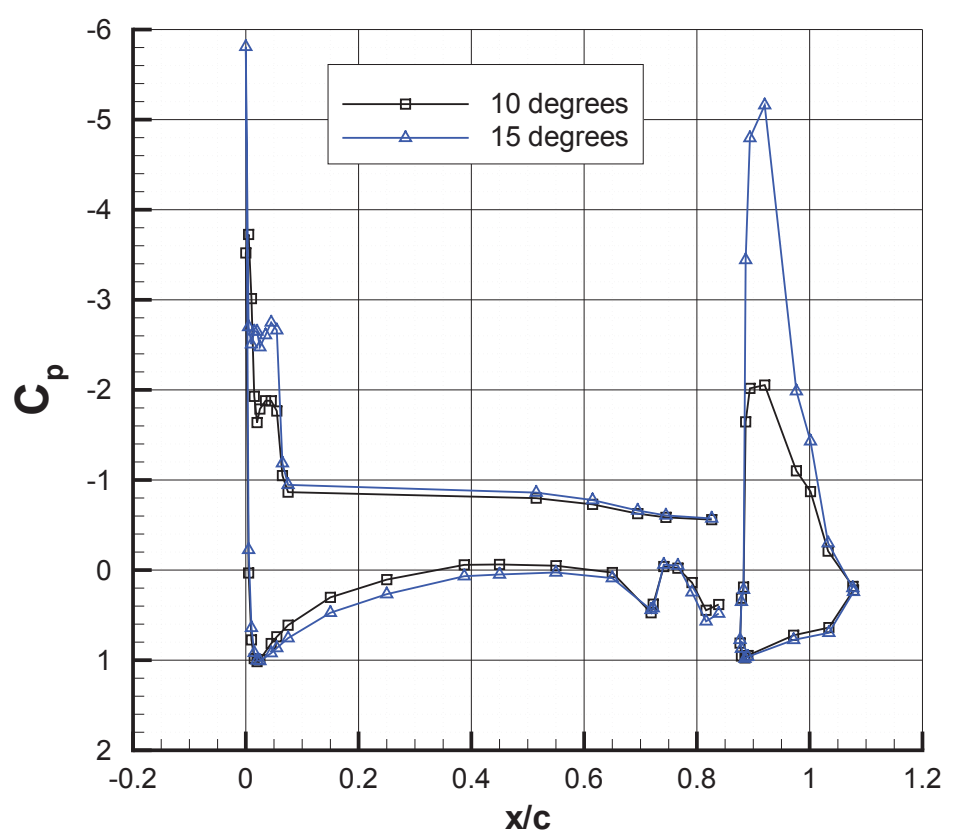

Figure 7. $C_{p}$ distribution over the main element and flap at $20 \mathrm{~m} / \mathrm{s}$. 


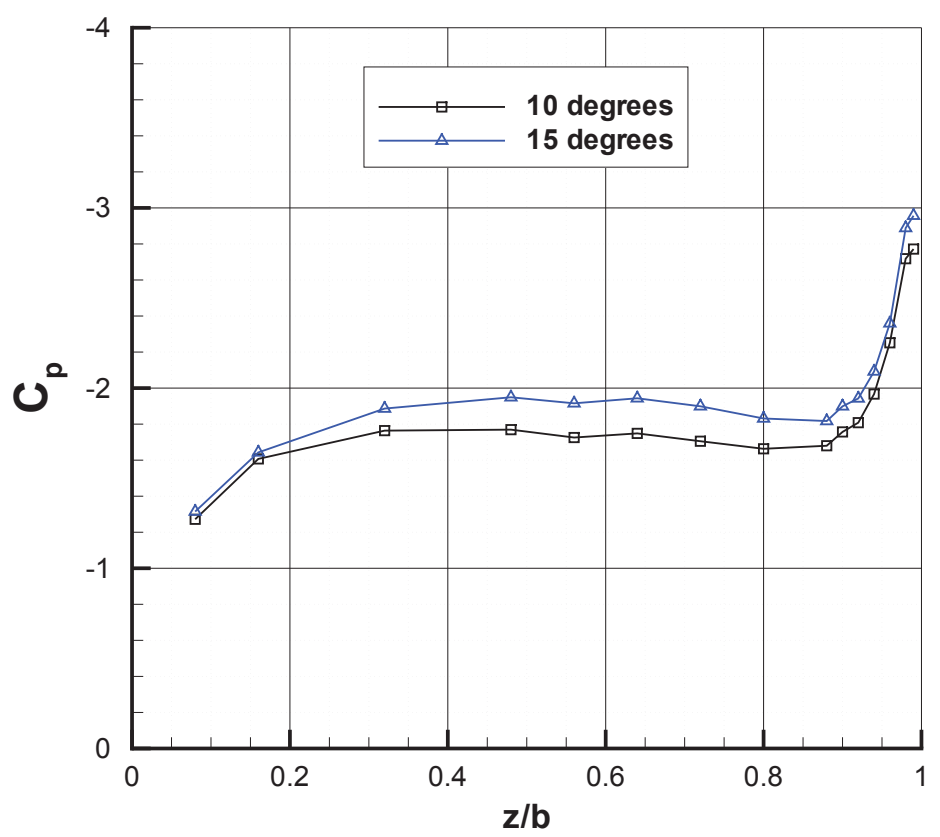

Figure 8. The spanwise $C_{p}$ distribution over the flap at $20 \mathrm{~m} / \mathrm{s}$.

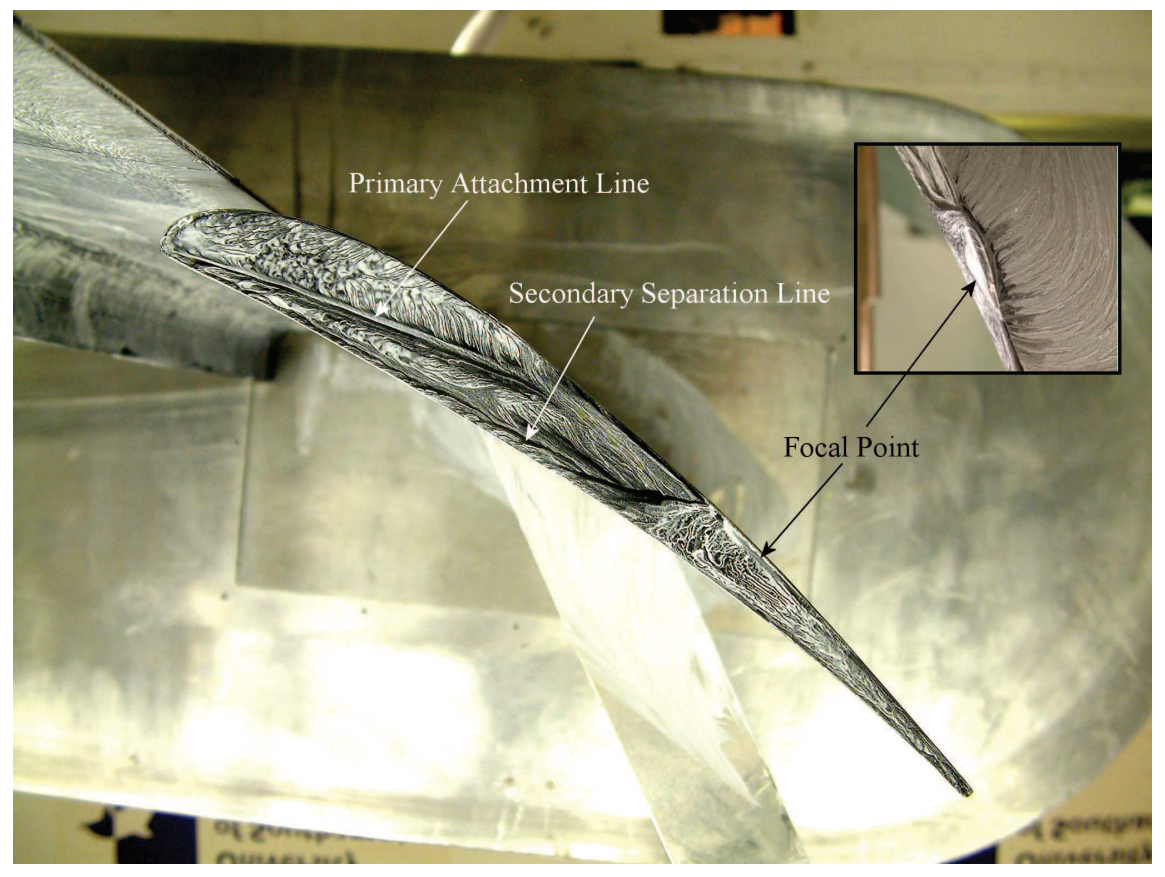

Figure 9. Oil flow of flap side edge showing major flow features. View looking starboard, flow is from left to right. 


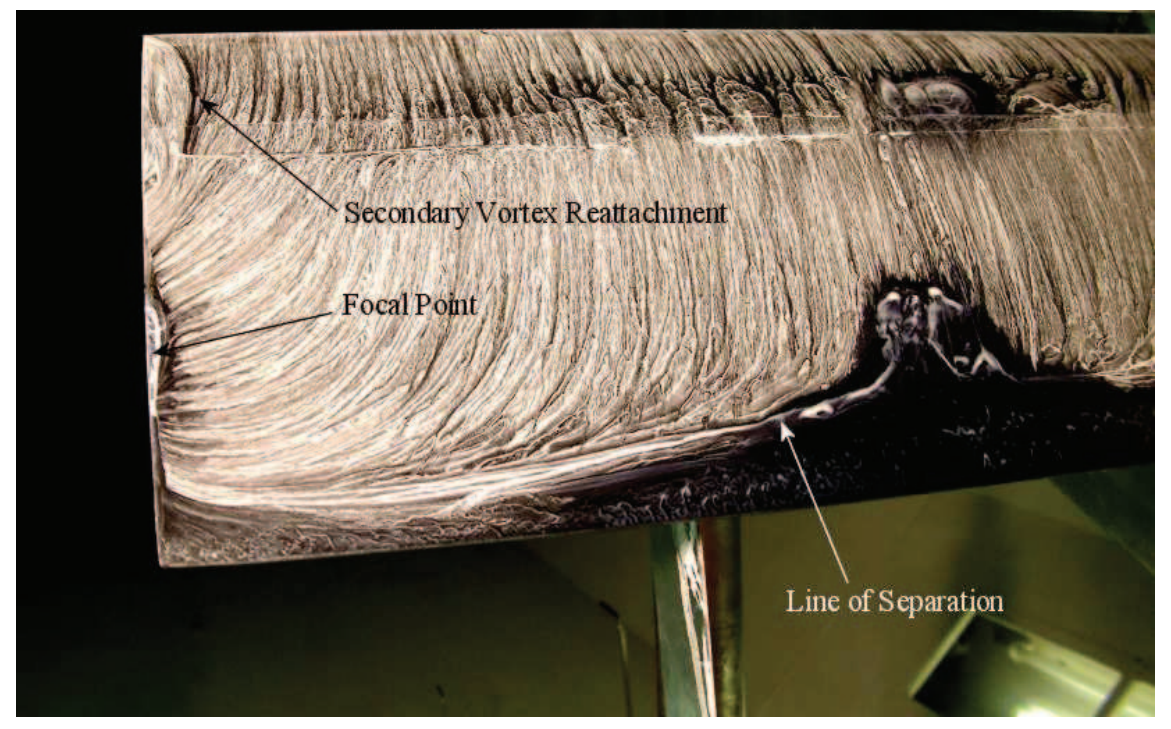

Figure 10. Oil flow of suction surface of flap. View looking upstream.

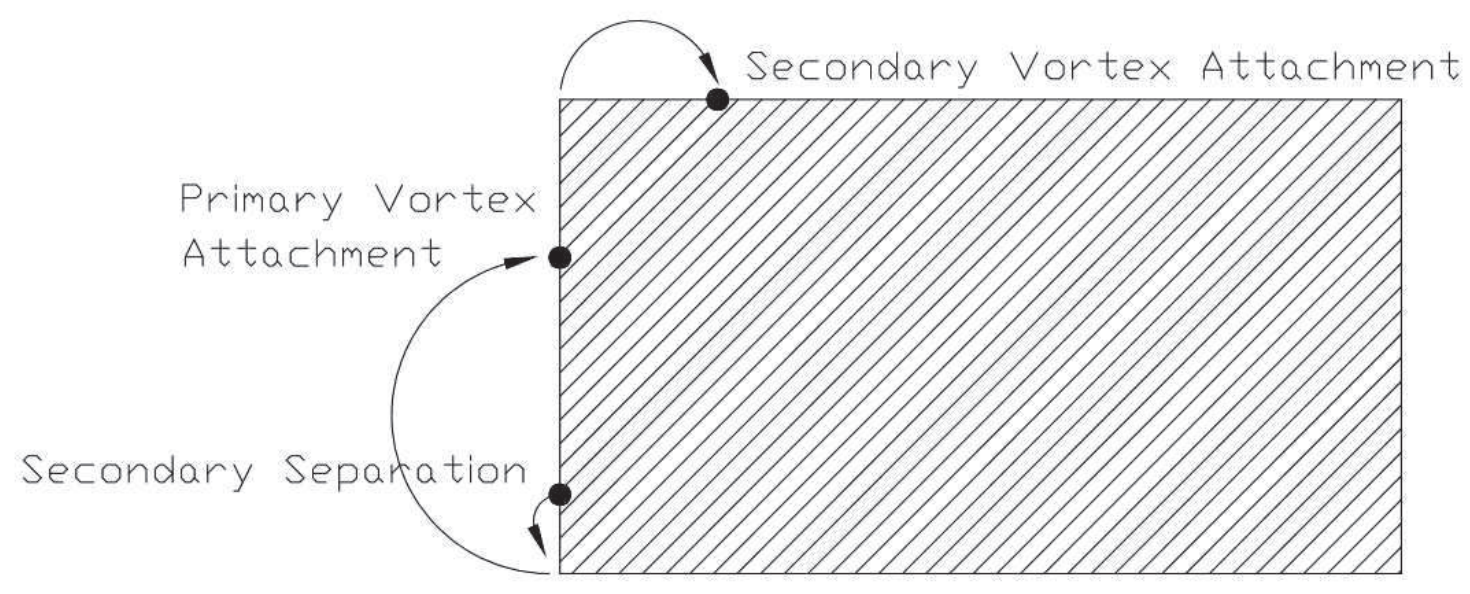

Figure 11. Schematic of flap side-edge flow in $y-z$ plane at $x_{F} / c_{F}=0.27$. View looking upstream.

\section{4 of 22}




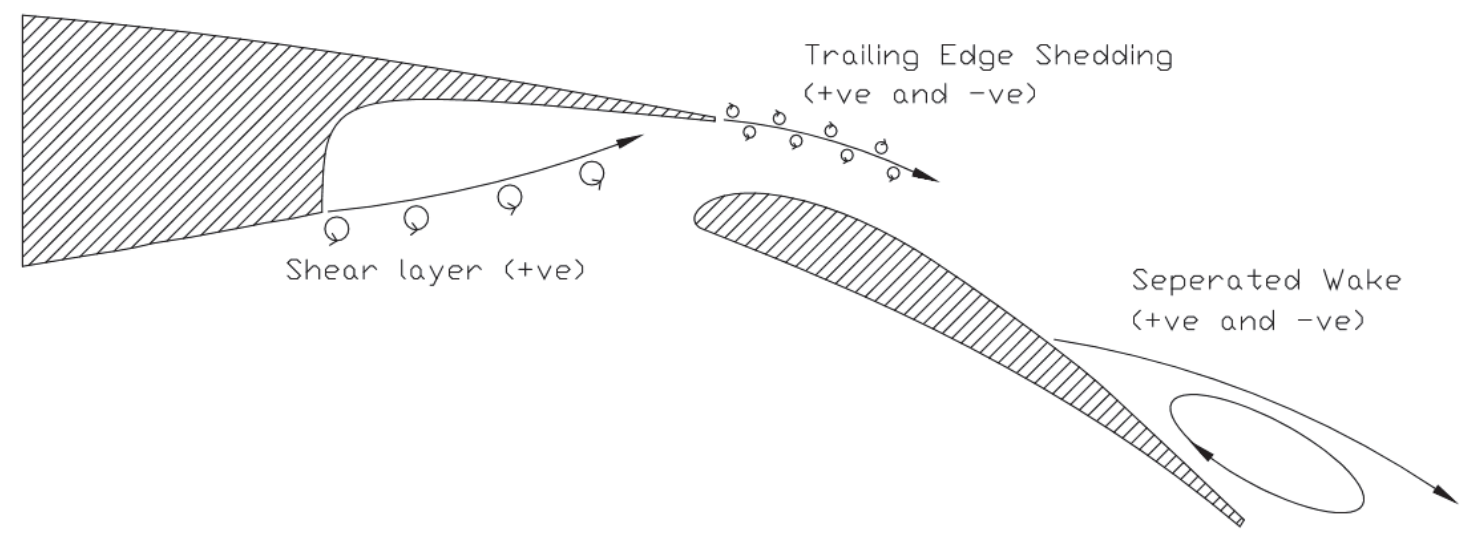

Figure 12. Schematic of vorticity sources in $x-y$ plane.

15 of 22 


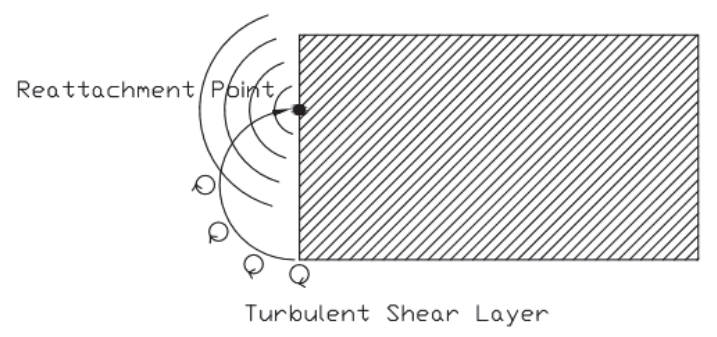

(a) $x_{F} / c_{F}=0.2$

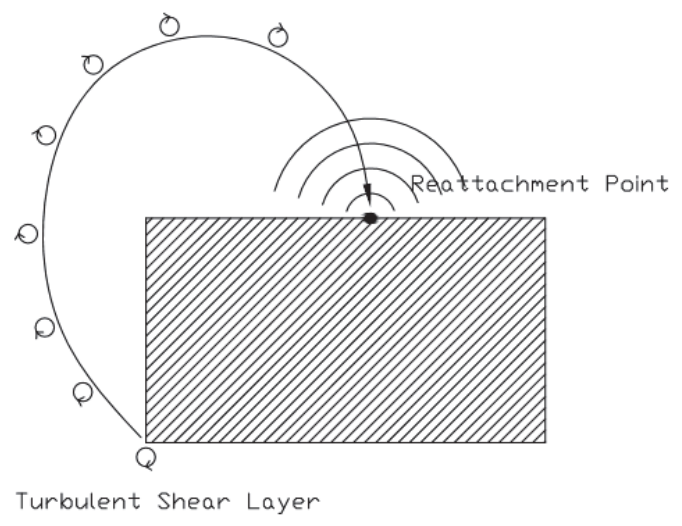

(b) $x_{F} / c_{F}=0.4$

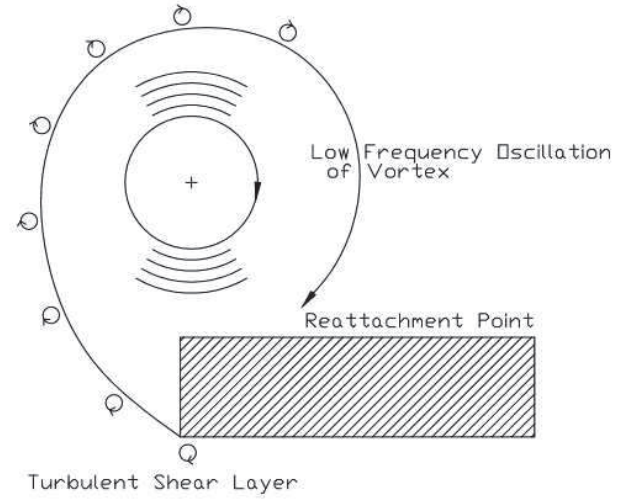

(c) $x_{F} / c_{F}=0.8$

Figure 13. Potential acoustic sources due to vorticity-surface interactions. 


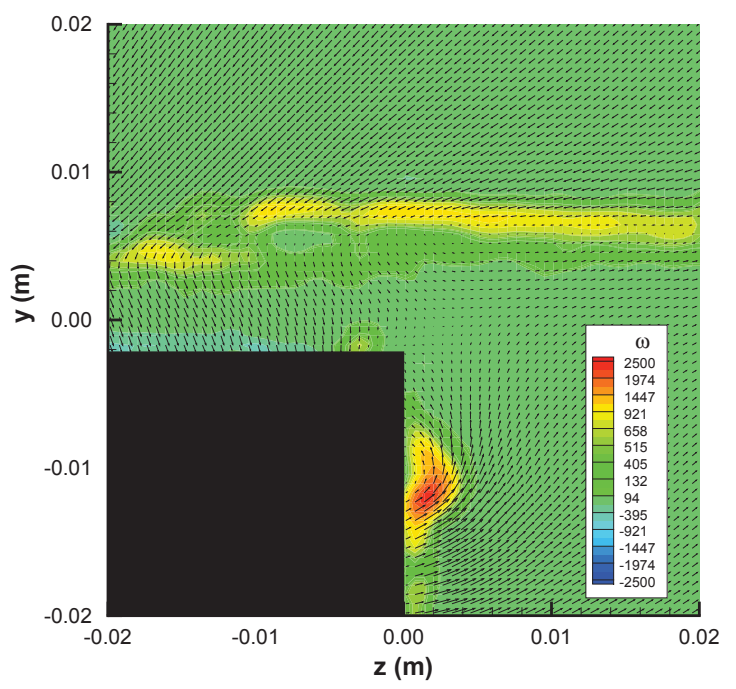

(a) $x_{F} / c_{F}=0.2$

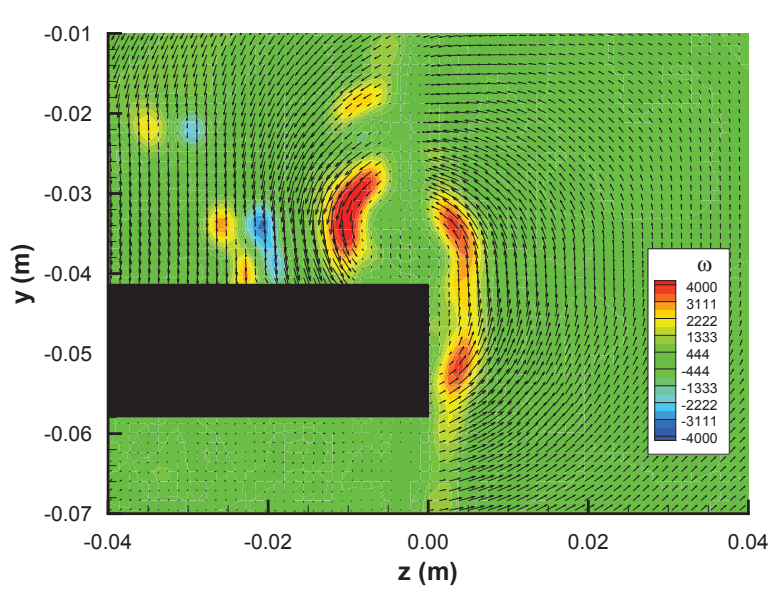

(c) $x_{F} / c_{F}=0.6$

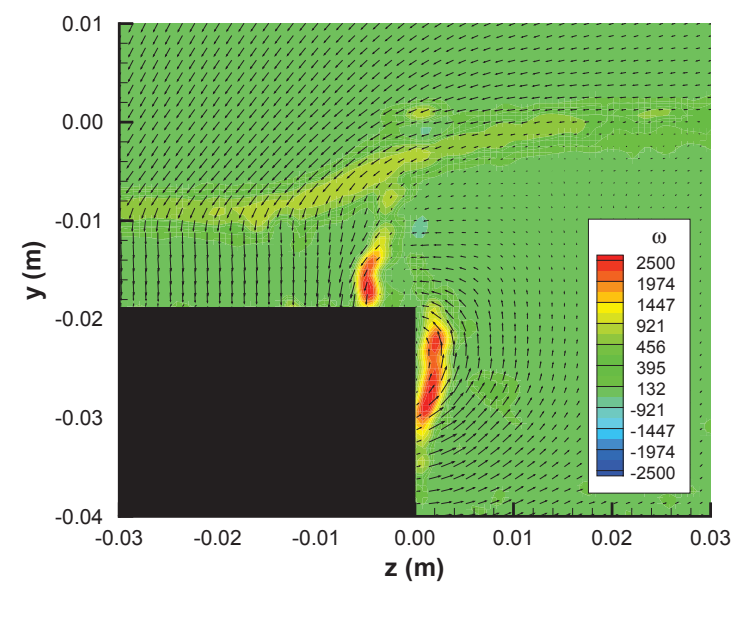

(b) $x_{F} / c_{F}=0.4$

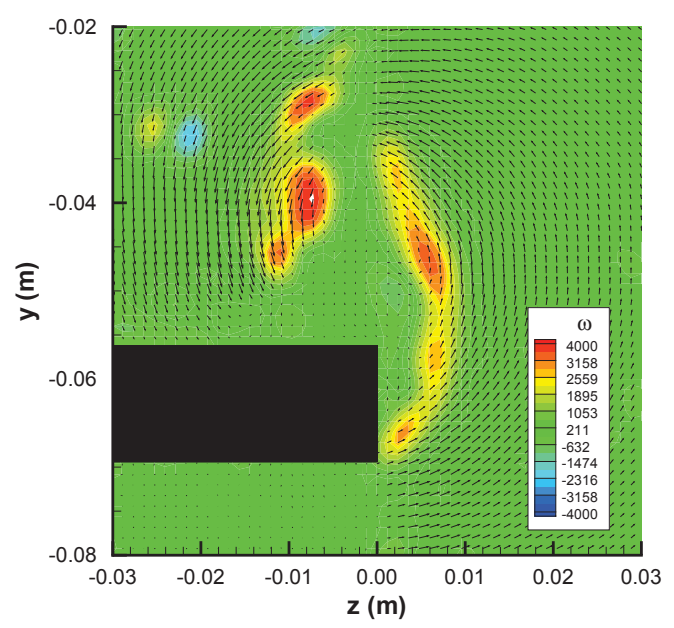

(d) $x_{F} / c_{F}=0.7$

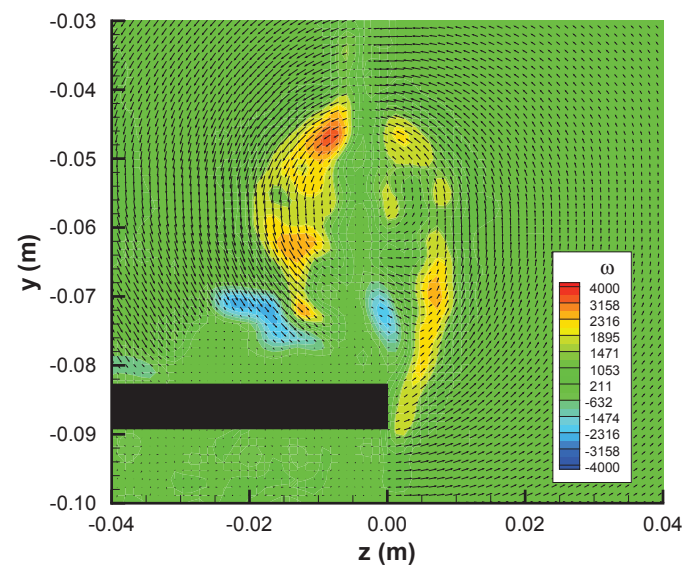

(e) $x_{F} / c_{F}=0.9$

Figure 14. PIV data for the hardwall case.

$$
17 \text { of } 22
$$

American Institute of Aeronautics and Astronautics 


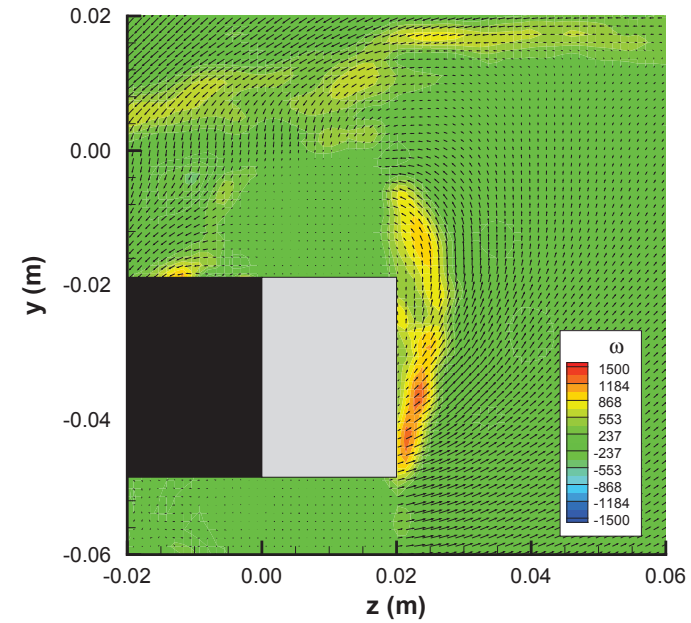

(a) $x_{F} / c_{F}=0.4$

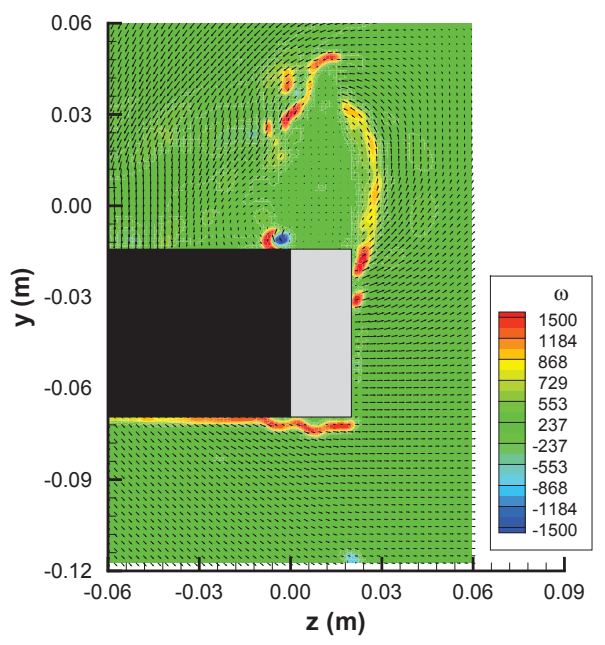

(c) $x_{F} / c_{F}=0.7$

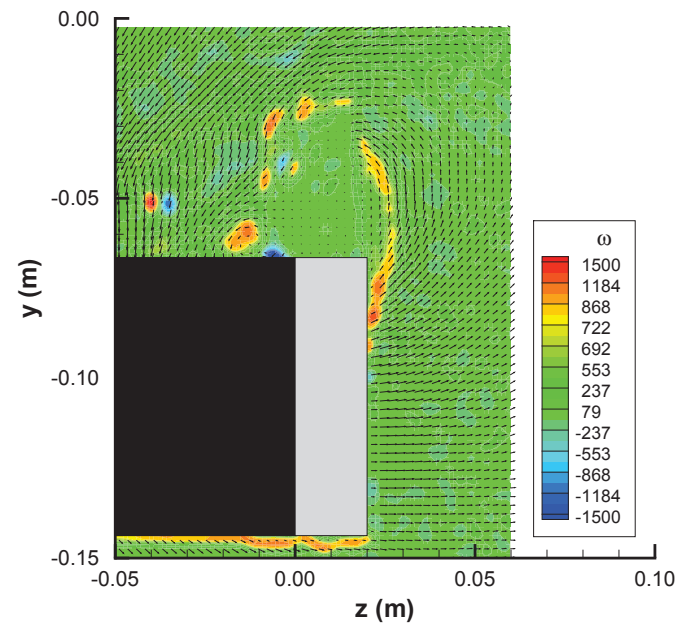

(b) $x_{F} / c_{F}=0.6$

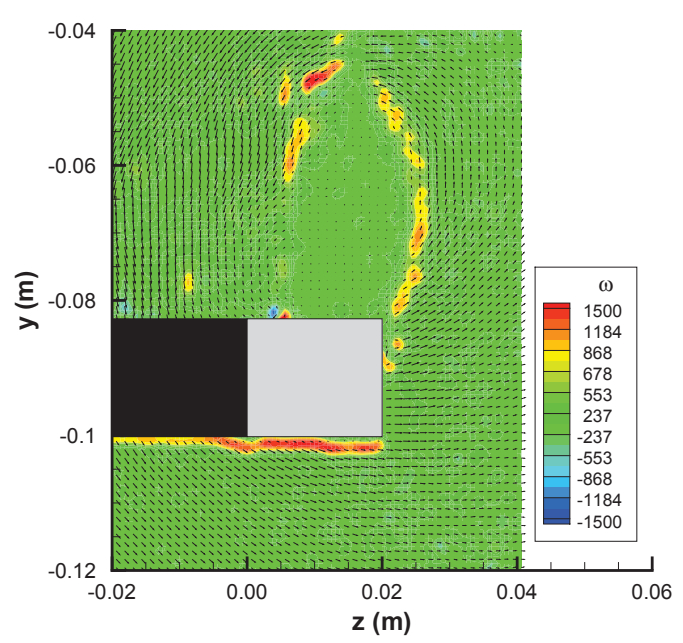

(d) $x_{F} / c_{F}=0.9$

Figure 15. PIV data for the 40 PPI $10-12 \%$ porous side-edge. 


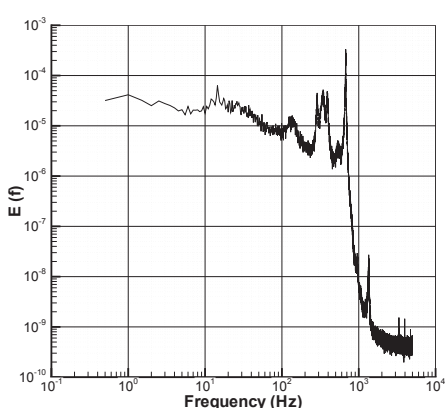

(a) $V_{\infty}=10 \mathrm{~m} / \mathrm{s}, \alpha=5 \mathrm{deg}, \delta_{F}=29$ deg, Position 1.

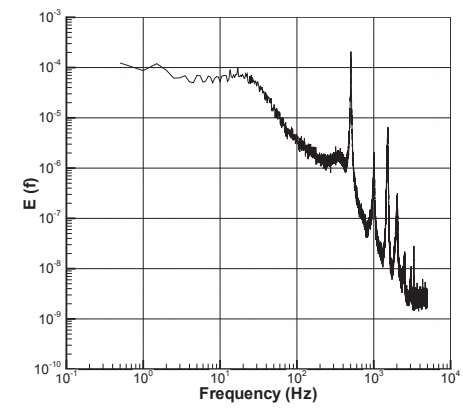

(d) $V_{\infty}=10 \mathrm{~m} / \mathrm{s}, \alpha=10 \mathrm{deg}, \delta_{F}=29$ deg, Position 2.

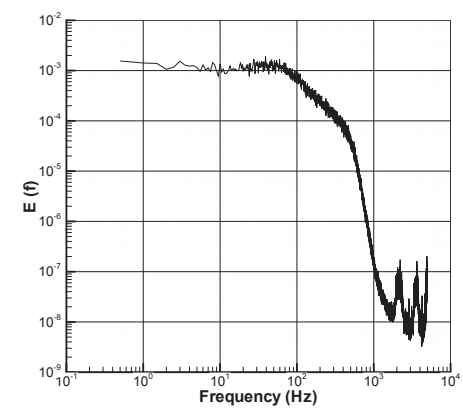

(g) $V_{\infty}=10 \mathrm{~m} / \mathrm{s}, \alpha=5 \mathrm{deg}, \delta_{F}=39$ deg, Position 3.

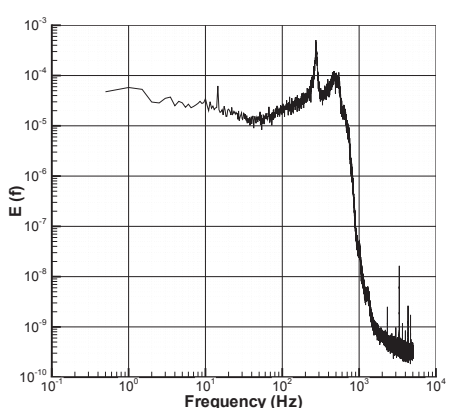

(b) $V_{\infty}=10 \mathrm{~m} / \mathrm{s}, \alpha=10 \mathrm{deg}, \delta_{F}=29$ deg, Position 1.

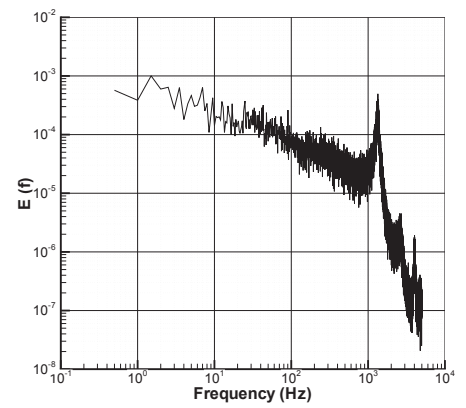

(e) $V_{\infty}=20 \mathrm{~m} / \mathrm{s}, \alpha=10 \mathrm{deg}, \delta_{F}=29$ deg, Position 2.

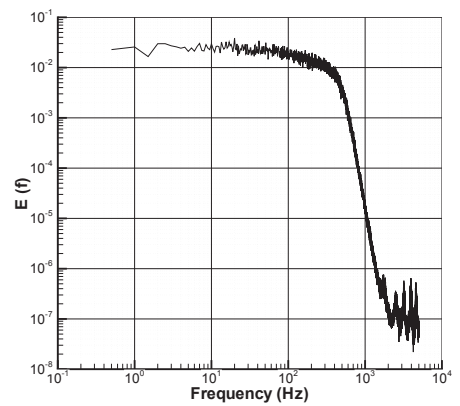

(h) $V_{\infty}=20 \mathrm{~m} / \mathrm{s}, \alpha=5 \mathrm{deg}, \delta_{F}=39$ deg, Position 3.

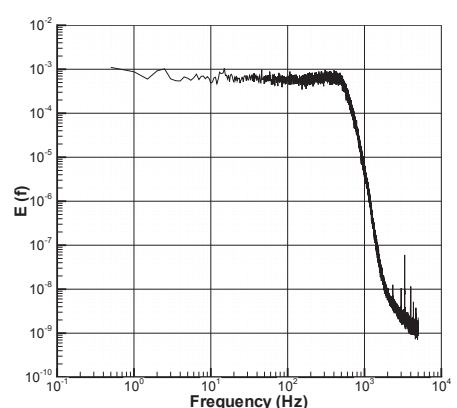

(c) $V_{\infty}=20 \mathrm{~m} / \mathrm{s}, \alpha=10 \mathrm{deg}, \delta_{F}=29$ deg, Position 1.

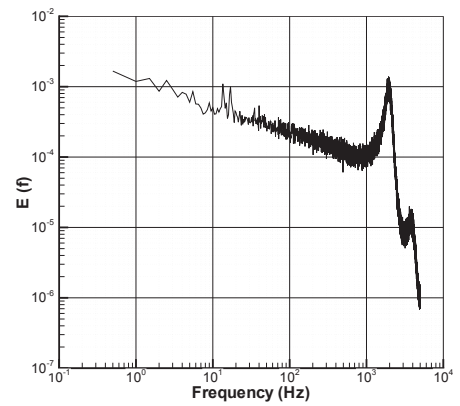

(f) $V_{\infty}=30 \mathrm{~m} / \mathrm{s}, \alpha=10 \mathrm{deg}, \delta_{F}=29$ deg, Position 2.

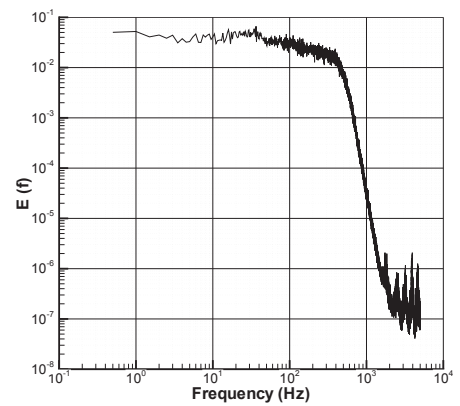

(i) $V_{\infty}=30 \mathrm{~m} / \mathrm{s}, \alpha=5 \mathrm{deg}, \delta_{F}=39$ deg, Position 3.

Figure 16. Hotwire measurements in the downstream vortex. 


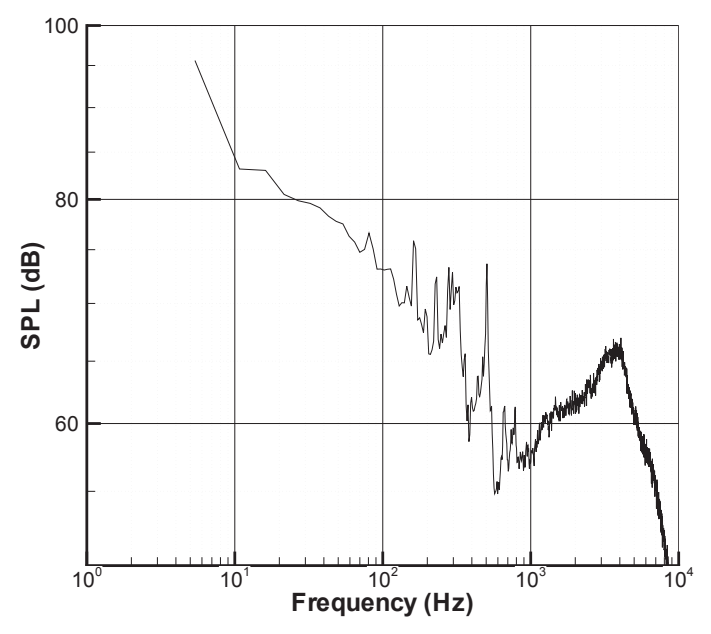

(a) $V_{\infty}=10 \mathrm{~m} / \mathrm{s}, \alpha=5 \mathrm{deg}, \delta_{F}=29 \mathrm{deg}$.

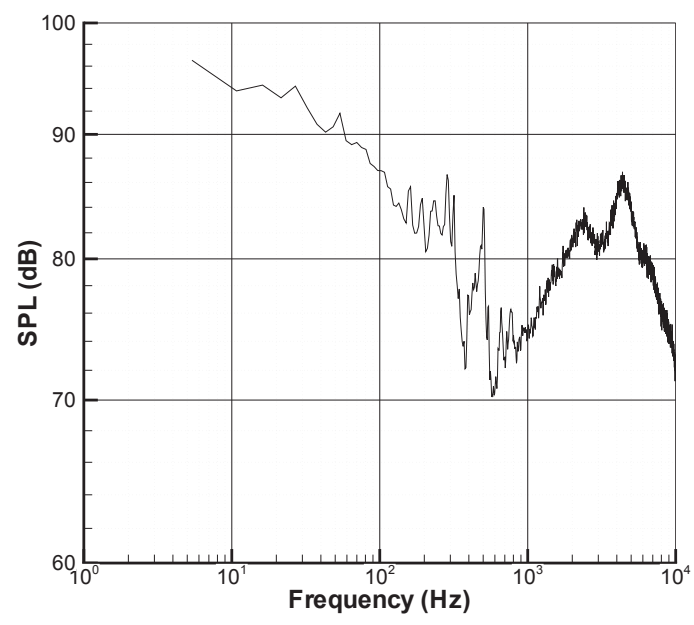

(c) $V_{\infty}=20 \mathrm{~m} / \mathrm{s}, \alpha=5 \mathrm{deg}, \delta_{F}=29 \mathrm{deg}$.

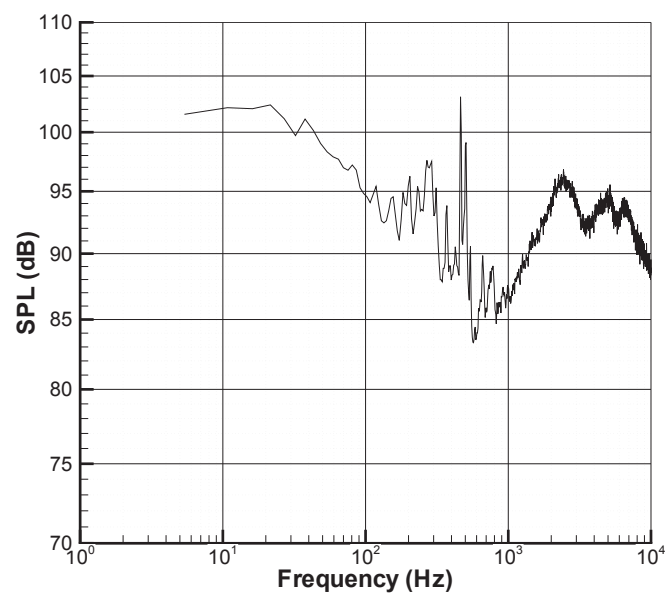

(e) $V_{\infty}=30 \mathrm{~m} / \mathrm{s}, \alpha=5 \mathrm{deg}, \delta_{F}=29 \mathrm{deg}$.

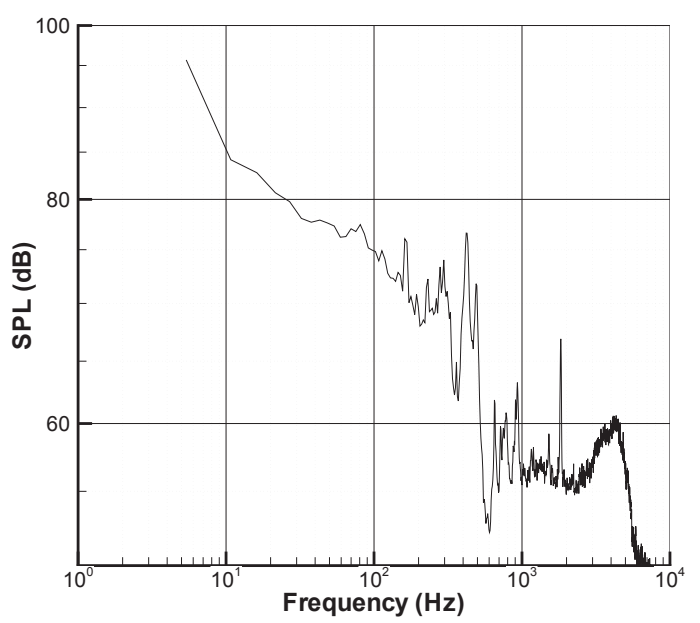

(b) $V_{\infty}=10 \mathrm{~m} / \mathrm{s}, \alpha=5 \mathrm{deg}, \delta_{F}=39 \mathrm{deg}$.

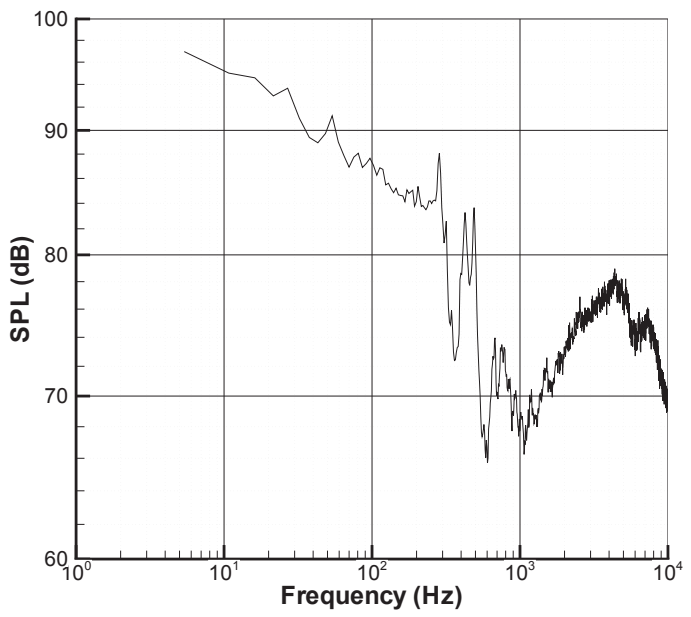

(d) $V_{\infty}=20 \mathrm{~m} / \mathrm{s}, \alpha=5 \mathrm{deg}, \delta_{F}=39 \mathrm{deg}$.

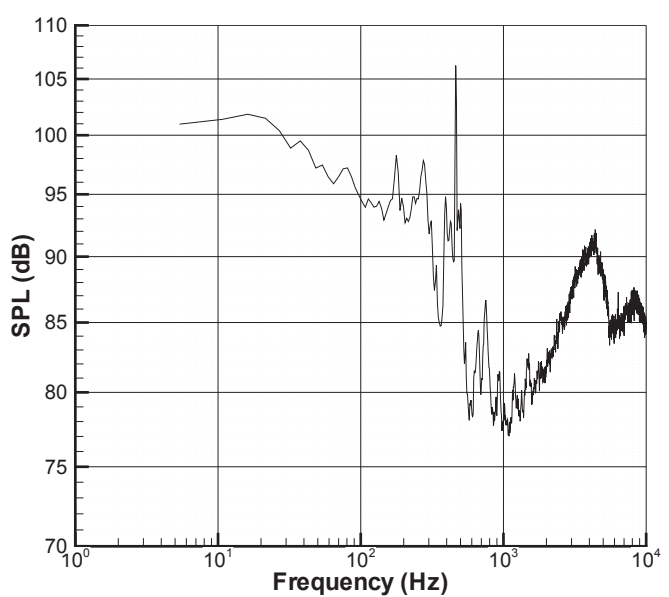

(f) $V_{\infty}=30 \mathrm{~m} / \mathrm{s}, \alpha=5 \mathrm{deg}, \delta_{F}=39 \mathrm{deg}$.

Figure 17. On-Surface microphone measurements for Mic 1 - hardwall case.

$$
20 \text { of } 22
$$




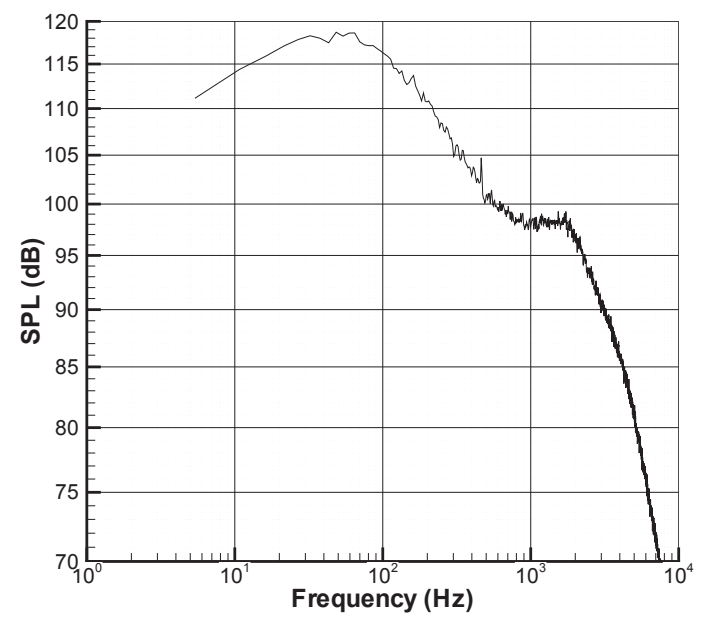

(a) $V_{\infty}=30 \mathrm{~m} / \mathrm{s}, \alpha=5 \mathrm{deg}, \delta_{F}=29 \mathrm{deg}$, Mic 2 .

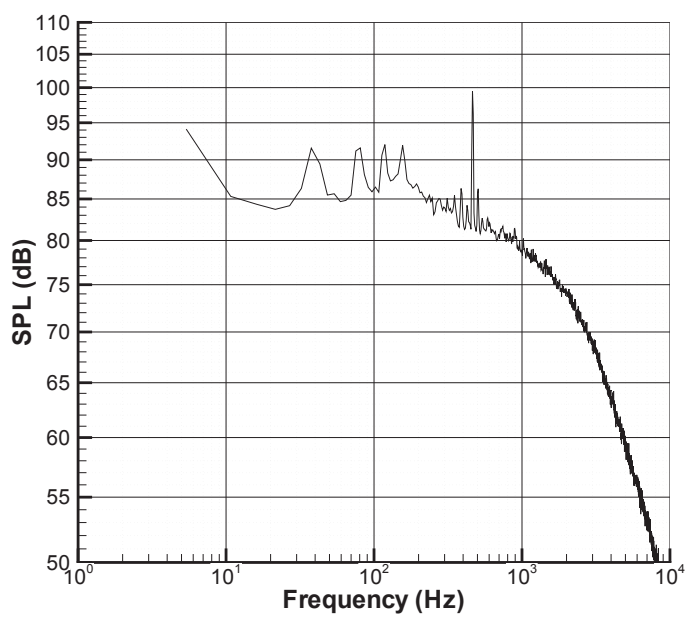

(b) $V_{\infty}=30 \mathrm{~m} / \mathrm{s}, \alpha=5 \mathrm{deg}, \delta_{F}=29 \mathrm{deg}$, Mic 3 .

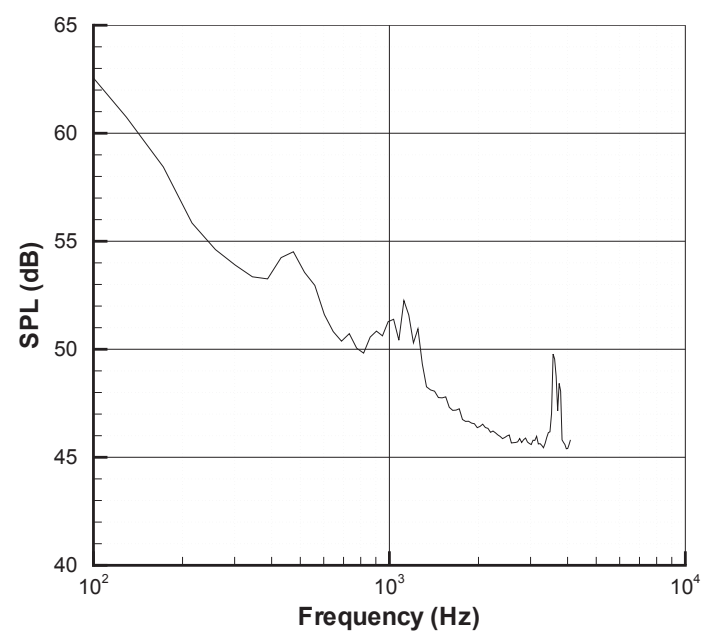

(c) $V_{\infty}=10 \mathrm{~m} / \mathrm{s}, \alpha=5 \mathrm{deg}, \delta_{F}=29 \mathrm{deg}$, Mic 4 .

Figure 18. On-surface microphone measurements for Mic 2, Mic 3 and Mic 4 - hardwall case. 


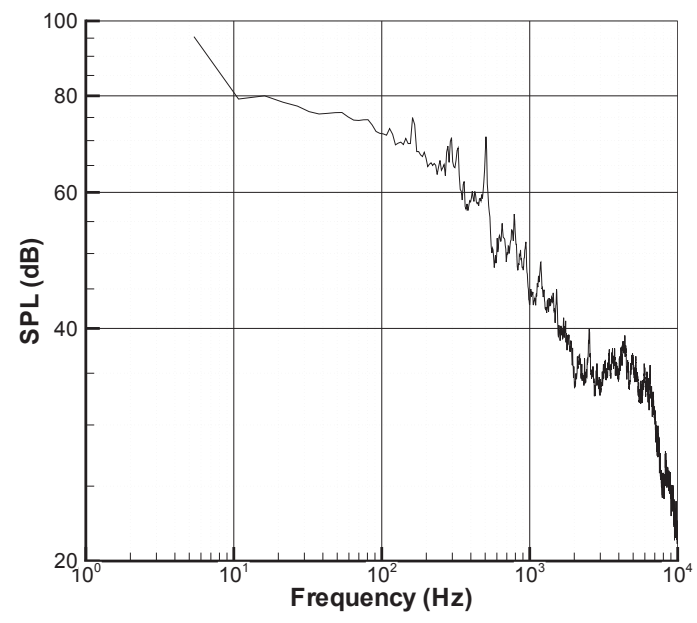

(a) $V_{\infty}=10 \mathrm{~m} / \mathrm{s}, \alpha=5 \mathrm{deg}, \delta_{F}=29 \mathrm{deg}$.

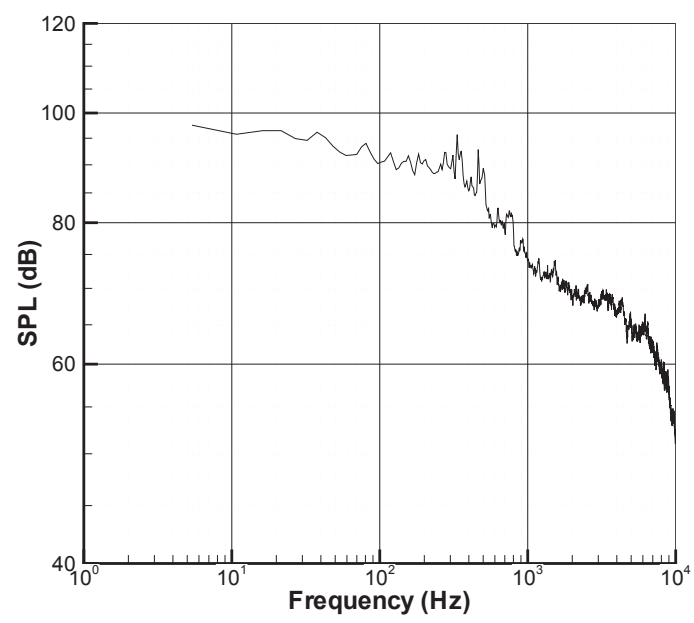

(c) $V_{\infty}=30 \mathrm{~m} / \mathrm{s}, \alpha=5 \mathrm{deg}, \delta_{F}=29 \mathrm{deg}$.

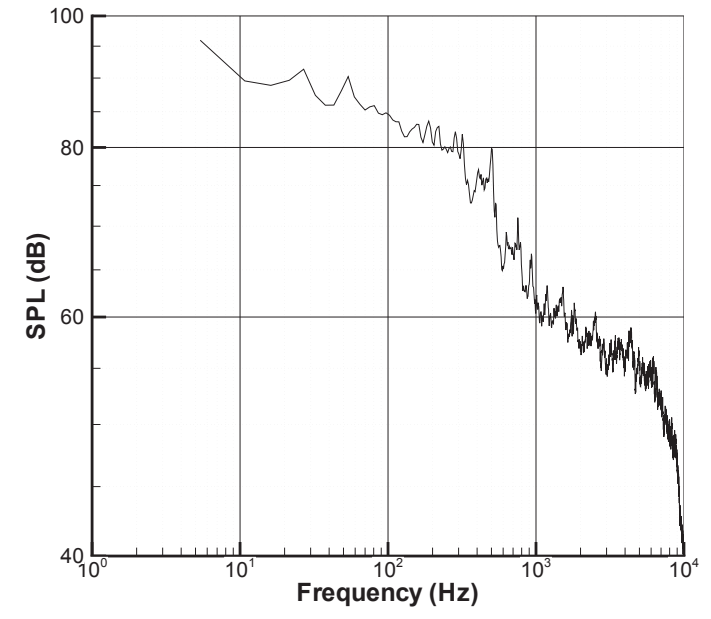

(b) $V_{\infty}=20 \mathrm{~m} / \mathrm{s}, \alpha=5 \mathrm{deg}, \delta_{F}=29 \mathrm{deg}$.

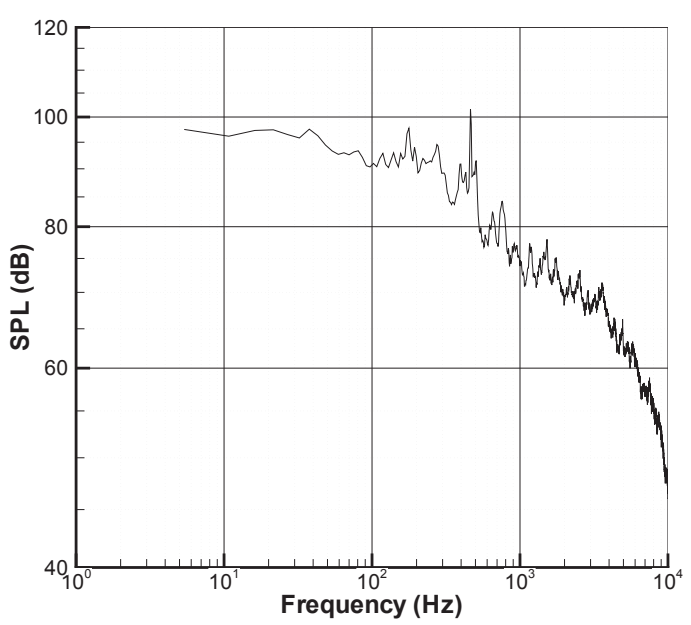

(d) $V_{\infty}=30 \mathrm{~m} / \mathrm{s}, \alpha=5 \mathrm{deg}, \delta_{F}=39 \mathrm{deg}$.

Figure 19. On-surface microphone measurements for Mic 1 - porous side-edge 40 PPI $10-12 \%$. 